\title{
Motivational characteristics of underrepresented ethnic and racial minority students in introductory physics courses
}

\author{
Z. Yasemin Kalender ${ }^{1}$, Emily Marshman ${ }^{1}$, Timothy J. Nokes-Malach ${ }^{2}$, Christian Schunn ${ }^{2}$, and Chandralekha Singh ${ }^{1}$ \\ ${ }^{I}$ Department of Physics and Astronomy, ${ }^{2}$ Learning Research and Development Center \\ University of Pittsburgh, Pittsburgh PA 15260
}

\begin{abstract}
Many hypotheses have been put forth to explain the under-representation and under-performance of historically marginalized racial and ethnic minority students in physics. While much research has focused on the relations between prior knowledge and performance, less work has examined the potential interactive role of student motivation. In particular, expectancy value theory posits that students' beliefs about their expectations for success (e.g., self-efficacy) and the value they associate with an academic task (e.g., intrinsic interest) influence their persistence and performance. In this study, we conducted a longitudinal analysis of students' motivational characteristics in introductory physics courses by administering surveys at three points during the year. White, Asian, and underrepresented racial/ethnic minority students' self-efficacy and interest in physics are reported, and implications for instruction are discussed.
\end{abstract}

\section{INTRODUCTION}

Research shows that students from underrepresented racial and ethnic backgrounds sometimes under-perform in physics courses and few major in physics-related fields [1,2]. Despite some attempts to increase diversity in physics courses and reduce the performance gaps by race/ethnicity in physics [3-5], the underlying causes of the low representation and relatively poor performance of racial/ethnic minorities are not well understood.

Much research in physics education has focused on improving learning outcomes through the development of pedagogies that build on students' prior knowledge and learning difficulties. Although many research-based instructional strategies have been effective in improving students' physics content knowledge and problem-solving skills, there has been little focus on how student motivation may interact with instruction and learning outcomes [6]. For instance, students' self-efficacy can affect their motivation to learn and, ultimately, learning outcomes [7]. Students' value and interest in a particular academic task can also affect students' persistence and learning [8]. Therefore, it is important to examine students' motivational characteristics when developing and implementing instructional strategies.

\section{BACKGROUND}

We describe a study in which we assessed students' intrinsic interest and self-efficacy throughout algebra-based and calculus-based introductory physics course sequences. We report White, Asian, and underrepresented racial/ethnic minority students' initial motivational characteristics and how these change over time. The findings have implications for the development and implementation of effective pedagogies to help all students learn.

Certain racial and ethnic groups have been traditionally underrepresented in physics, including African Americans, Latinx/Hispanics, American Indians, and Pacific Islanders
[1]. Furthermore, students from these underrepresented groups often underperform in physics courses [2]. Although prior work has focused on performance differences between underrepresented students and majority students, less work has examined the motivation of underrepresented racial/ethnic minority students in physics courses.

Expectancy value theory posits that students' expected success in performing a task as well as the value they associate with the task can influence their persistence and performance in academic settings [9]. Expectancy involves one's beliefs about his or her own level of ability and expectations of success, e.g., self-efficacy, which is the belief in one's capability to be successful in a particular task, subject area, or course [10]. Even after controlling for students' prior knowledge and skills, higher self-efficacy is positively correlated with grades in physics [10]. Value includes several components such as intrinsic value (enjoyment from doing a task, or interest), attainment value (how important one feels to do well on the task), and utility value (usefulness of task in achieving goals) [9].

Since there have been relatively few longitudinal studies focusing on underrepresented racial/ethnic minority students' self-efficacy and intrinsic interest in physics [11], we investigated students' motivational characteristics at three time points during a two-semester algebra-based and calculus-based introductory physics course sequence. The findings can be a stepping stone to developing and implementing learning tools in order to help all students succeed in physics courses. The investigation can also help determine the motivational factors for which there are initial differences by race/ethnicity or whether differences develop across courses.

\section{METHODOLOGY}

We selected a set of six motivational constructs based on a review of prior research on learning and motivation. Two 
of the motivational constructs that related to expectancy value theory involved self-efficacy and fascination with physics (i.e., intrinsic valuing of physics). We also investigated other motivational constructs including value associated with physics (i.e., importance of the knowledge of physics), students' intelligence mindset (i.e., students beliefs about whether intelligence is a fixed trait that one is born with or is malleable and can be shaped by the environment), grit (i.e., the capacity to sustain both effort and interest even in the absence of positive feedback), and physics epistemology (i.e., beliefs about what constitutes physics knowledge and how that knowledge is acquired). A survey was constructed to cover the core aspects of each construct with attention to minimize total survey length. The survey consisted of 29 items adapted from prior surveys from the motivation literature [12-16]. Table I shows example survey items for each motivational construct. Here, we focus on students' self-efficacy and fascination with physics (i.e., intrinsic value associated with physics). We do not focus on students' responses to the "valuing physics" items since those questions focused on general views about the importance of physics knowledge but were not directly related to students' intrinsic value, attainment value, or utility value.

We administered the survey in a written format to students at a large research university in the U.S. Students in algebra-based and calculus-based classes were asked to respond to survey questions at the beginning of Physics 1 in the fall semester, the beginning of Physics 2 in the spring semester, and also at the end of Physics 2 in the spring semester. Physics 1 courses cover topics involving Newtonian mechanics and Physics 2 courses include topics related to electricity and magnetism. Most of the courses were in a traditional, lecture-based format. Students in calculus-based classes are mostly freshmen who are engineering or physical science majors. Students in algebrabased physics courses are mostly juniors who intend to pursue careers in health related fields or biology. The survey was completed by most students in about 10-15 minutes.

For each survey item, students were given a score of 1-4. For the items related to fascination and self-efficacy, a high score means that a student is highly fascinated by physics and has a high level of self-efficacy. Students were given an average score for self-efficacy and fascination. For example, a student who answered "Yes!" to two of the fascination with physics questions and "no" to one of them would have an average fascination score of $(4+4+2) /(3$ questions $)=3.33$.

At the beginning of the fall and spring courses, we analyzed the internal consistency of the subscales, i.e., fascination, value, self-efficacy, intelligence mindset, grit, and physics epistemology. Analysis showed that all Cronbach's alphas for the targeted constructs were above 0.60 , which is considered fairly good [17]. The scales with five or more items all had a Cronbach's alpha of 0.70 or higher. No substantial increases in alpha for any of the scales could have been achieved by eliminating items. To establish
Table I. Motivational factors with the number of items, example survey items, and scale.

\begin{tabular}{|c|c|c|}
\hline Factor & Example Survey Item & Scale \\
\hline $\begin{array}{c}\text { Fascination } \\
\text { with Physics } \\
3 \text { items }\end{array}$ & $\begin{array}{l}\text { I wonder about how nature } \\
\text { works ... }\end{array}$ & $\begin{array}{c}\text { Never } \\
\text { Once a month } \\
\text { Once a week } \\
\text { Every day }\end{array}$ \\
\hline $\begin{array}{l}\text { Valuing } \\
\text { Physics } \\
5 \text { items }\end{array}$ & $\begin{array}{l}\text { Knowing physics is important } \\
\text { for being a good citizen. }\end{array}$ & $\begin{array}{c}\text { No! } \\
\text { no } \\
\text { yes } \\
\text { Yes! } \\
\end{array}$ \\
\hline $\begin{array}{l}\text { Self-Efficacy } \\
6 \text { items }\end{array}$ & $\begin{array}{l}\text { I am often able to help my } \\
\text { classmates with physics in the } \\
\text { laboratory or in recitation. }\end{array}$ & $\begin{array}{c}\text { No! } \\
\text { no } \\
\text { yes } \\
\text { Yes! }\end{array}$ \\
\hline $\begin{array}{l}\text { Intelligence } \\
\text { Mindset } \\
4 \text { items }\end{array}$ & $\begin{array}{l}\text {-You have a certain amount of } \\
\text { intelligence, and you can't really } \\
\text { do much to change it. } \\
\text {-Anyone can become good at } \\
\text { solving physics problems } \\
\text { through hard work. }\end{array}$ & $\begin{array}{l}\text { Strongly disagree } \\
\text { Disagree } \\
\text { Agree } \\
\text { Strongly agree }\end{array}$ \\
\hline $\begin{array}{c}\text { Grit } \\
3 \text { items }\end{array}$ & $\begin{array}{l}\text {-I often set a goal but later } \\
\text { choose to pursue a different one. } \\
\text {-I finish whatever I begin. }\end{array}$ & $\begin{array}{c}\text { Not like me at all } \\
\text { Not much like me } \\
\text { Somewhat like me } \\
\text { Mostly like me } \\
\text { Very much like } \\
\text { me }\end{array}$ \\
\hline $\begin{array}{c}\text { Physics } \\
\text { Epistemology } \\
8 \text { items }\end{array}$ & $\begin{array}{l}\text { I do not expect to understand } \\
\text { physics equations in an intuitive } \\
\text { sense; they must just be taken as } \\
\text { givens. }\end{array}$ & \begin{tabular}{|c|} 
Strongly disagree \\
Disagree \\
Agree \\
Strongly agree
\end{tabular} \\
\hline
\end{tabular}

the separability of the different subscales along with the validity of items as clear indicators of the scale to which they were assigned, we performed an exploratory factor analysis on the items in the survey based upon the early spring data. A principal components analysis was used, and the initial eigenvalues indicated that the first six components (all with eigenvalues greater than 1) explained a total of $49 \%$ of the variance (the $7^{\text {th }}$ component explained only an additional $4 \%$ of the variance). The data supported the existence of six separable scales, and items loaded on the scales as intended.

After linking students' responses to their demographic information, we separated the students into three groups: White, Asian, and underrepresented racial/ethnic minority students. Underrepresented racial/ethnic minority students are those who reported their race/ethnicity as Black, Hispanic, American Indian, Pacific Islander, or Multi-Racial including one of these races. We examined these racial

Table II. The number of White (W), Asian (A), and underrepresented racial/ethnic minority (U) students who took the survey at the three time points.

\begin{tabular}{|c|l|l|l|}
\hline & $\begin{array}{c}\text { Beginning of } \\
\text { Physics 1 }\end{array}$ & $\begin{array}{c}\text { Beginning of } \\
\text { Physics 2 }\end{array}$ & \multicolumn{1}{|c|}{$\begin{array}{c}\text { End of } \\
\text { Physics 2 }\end{array}$} \\
\hline $\begin{array}{c}\text { Calculus- } \\
\text { based }\end{array}$ & $\mathrm{N}=364 \mathrm{~W}, 57$ & $\mathrm{~N}=219 \mathrm{~W}, 39$ & $\mathrm{~N}=178 \mathrm{~W}$, \\
$\mathrm{A}, 42 \mathrm{U}$ & $\mathrm{A}, 21 \mathrm{U}$ & $32 \mathrm{~A}, 12 \mathrm{U}$ \\
\hline $\begin{array}{c}\text { Algebra- } \\
\text { based }\end{array}$ & $\mathrm{N}=285 \mathrm{~W}, 82$ & $\mathrm{~N}=150 \mathrm{~W}, 52$ & $\mathrm{~N}=123 \mathrm{~W}$, \\
& $\mathrm{A}, 50 \mathrm{U}$ & $\mathrm{A}, 16 \mathrm{U}$ & $40 \mathrm{~A}, 13 \mathrm{U}$ \\
\hline
\end{tabular}




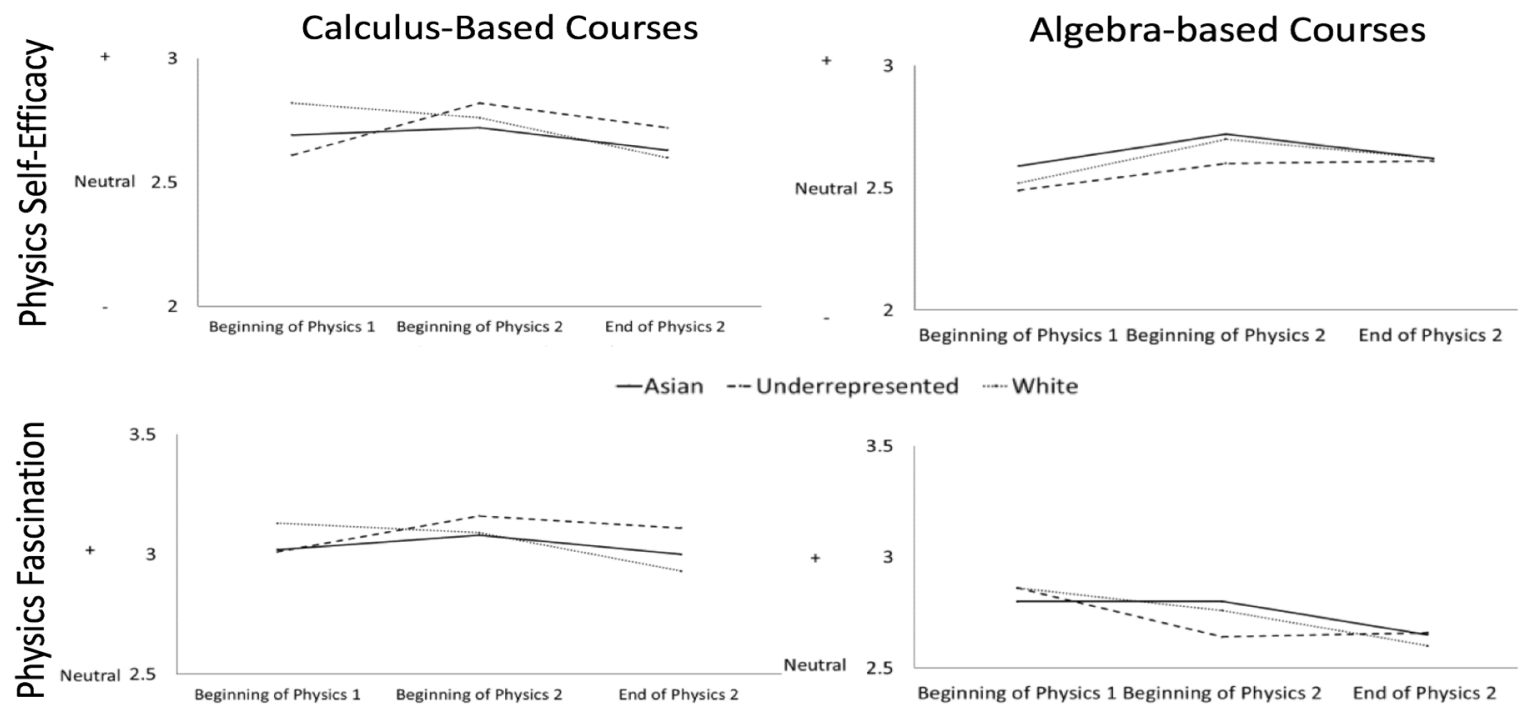

Figure 1. Physics Self-Efficacy (top row) and Fascination (bottom row) in calculus-based (left column) and algebra-based (right column) introductory physics sequences. "+”and “-” signs indicate positive and negative responses.

categories because there are positive (for Asians) and negative (underrepresented students) stereotypes for performance in science, and because there were too few underrepresented racial/ethnic minority students to further divide them in the in the analyses. Black, Hispanic, American Indian, Pacific Islander, and Multi-Racial students have been underrepresented in STEM fields, and in particular, physics [1]. Table II shows the number of students in each ethnic/racial group at the three time points at which the survey was given.

\section{RESULTS}

See Figure 1 for students' average self-efficacy scores in physics courses. An ANOVA showed that at the beginning of calculus-based Physics 1, there was a statistically significant difference in students' self-efficacy scores in the three racial/ethnic groups $(F(2,460)=5.42, p=0.005)$. White students initially had the highest self-efficacy score whereas underrepresented racial/ethnic minority students' selfefficacy is the lowest at the beginning of calculus-based Physics 1 . We observed that underrepresented racial/ethnic minority students' self-efficacy score increased significantly more than White and Asian students between the beginning of calculus-based Physics 1 and $2(F(2,277)=4.22, p=0.016)$ and the differences in the self-efficacy of the three groups was eliminated. By the end of calculus-based Physics 2, we observed that all students' self-efficacy did not change significantly with respect to the beginning of Physics 2 and all three groups had approximately the same self-efficacy score (see upper left graph in Figure 1). In algebra-based physics courses, statistical analyses showed that there was not a significant difference in the self-efficacy of students in the three groups at the beginning of Physics 1. Also, students' self-efficacy stayed approximately the same throughout algebra-based Physics 1 and Physics 2.

We now describe students' fascination with physics (i.e., their intrinsic interest in physics) throughout introductory physics course sequences. At the beginning of calculusbased Physics 1, statistical analyses showed that there was no significant difference in students' fascination scores in the three racial/ethnic groups. Also, students' fascination remained approximately the same throughout calculus-based Physics 1 and Physics 2. Students from underrepresented racial/ethnic minority groups reported the highest fascination with physics at the end of calculus-based Physics 2. In algebra-based physics courses, statistical analyses showed that there was not a significant difference in the fascination of students in the three racial/ethnic groups at the beginning of Physics 1 . Students in algebra-based physics courses reported lower levels of fascination with physics than students in calculus-based physics courses, and all students' fascination with physics decreased slightly by the end of algebra-based Physics 2.

\section{DISCUSSION AND SUMMARY}

In calculus-based physics courses, underrepresented racial/ethnic minority students initially had lower selfefficacy than White and Asian students. Underrepresented racial/ethnic minority students who persisted throughout calculus-based physics courses showed an increase in selfefficacy after Physics 1 and the gap between underrepresented racial/ethnic minority students and majority students' self-efficacy was reduced. Underrepresented racial/ethnic minority students also reported approximately the same level of fascination with physics as White and Asian students throughout the 
calculus-based physics course sequence. On the other hand, students who persisted in the algebra-based physics courses reported approximately the same self-efficacy and fascination throughout the courses, regardless of their race/ethnicity. Furthermore, students in algebra-based physics courses reported lower fascination with physics than students in calculus-based physics courses, and their fascination decreased by the end of Physics 2 .

In terms of Expectancy Value Theory, our results suggest that students who persist in taking physics courses for engineering and physical science fields tend to value physics, i.e., they have an intrinsic interest in physics, regardless of what racial/ethnic group they belong to. However, underrepresented racial/ethnic minority students in calculus-based physics courses tend to enter Physics 1 with lower expected success in the course (e.g., lower selfefficacy) than White and Asian students. It is possible that underrepresented racial/ethnic minority students initially have lower self-efficacy than White students because they feel that they do not belong or an awareness of the stereotype that minority students underperform in STEM fields. Our findings suggest that underrepresented racial/ethnic minority students who successfully progress in the calculus-based physics course sequence gain feedback about their ability in relation to other students (e.g., all students struggle in physics). This feedback informs them about their ability to succeed and increases their self-efficacy. It is also possible that underrepresented racial/ethnic minority students' intrinsic interest in physics and attainment value in physics (i.e., it is important to them to do well in physics to disconfirm negative stereotypes about underrepresented racial/ethnic minority students in STEM fields) are important factors for persisting in physics courses.

In contrast, students who succeed in progressing through an algebra-based physics course sequence for biology and health fields are less intrinsically interested in physics than students in the calculus-based courses. Furthermore, their intrinsic value associated with physics decreases throughout an introductory physics course sequence, regardless of what racial/ethnic group they belong to. Our findings suggest that students in algebra-based physics courses have less intrinsic interest in physics perhaps because they do not see the relevance of physics to their major/career goals (they intend to pursue careers in health related fields or biology). These students' motivation to persist in physics courses may be due, in part, to the utility value in that successfully completing the physics course sequence helps them achieve future goals since physics courses are required for their majors.

Instructors, researchers, and curriculum developers in physics can use these findings to develop and implement effective approaches and learning tools, in part, by taking into account students' motivational characteristics. Focusing on students' motivational characteristics, especially those of underrepresented racial/ethnic minority students, may prove fruitful in helping them succeed in physics courses and increase diversity in physics-related fields. The findings of this study suggest that it may be beneficial to provide explicit support to improve underrepresented racial/ethnic minority students' self-efficacy in physics courses for engineers and physical scientists to help more of them persist and succeed in those physics courses. For example, discussions early on in the physics course sequence that focus on effective study strategies, attributing success to hard work (as opposed to ability), and the fact that many students struggle in physics may improve underrepresented racial/ethnic minority students' self-efficacy and motivate them to persist in physics course sequences for engineers and scientists. In physics courses for students in biology and health-related fields, it may be useful to help students see the relevance of physics to health and biology related fields in order to motivate them to engage more deeply with course instruction. We plan to collect more data in the following semesters to draw stronger conclusions and investigate how the motivational characteristics discussed here relate to the type of instruction and learning over time in physics courses.

\section{ACKNOWLEDGEMENT}

This study was supported by NSF award DUE-1524575.
[1] https://www.nsf.gov/statistics/2017/nsf17310/data.cfm

[2] E. Brewe, V. Sawtelle, L. Kramer, G. O'Brien, I. Rodriquez, P. Pamela, Phys. Rev. ST PER 6, 010106 (2010)

[3] P. Heller \& M. Hollabaugh, Am. J. Phys. 60, 637 (1992).

[4] R. Steinberg \& K. Donnelly, Phys. Teach., 40, 108 (2002).

[5] A. Maries, C. Singh, (2016); doi: http://dx.doi.org/10.1063/1.4937713

[6] A. Wood, R. Galloway, R. Donnelly, J. Hardy, PRPER 12, 010140 (2016).

[7] R. Lent, S. Brown, K. Larkin, J. Counsel. Psych. 33, 265 (1986).

[8] P. Pintrich, J. of Educ. Psy. 95(4), 667-686 (2003).

[9] A. Wigfield \& J. Eccles, Contemporary Educational Psychology, pp. 68-81 (2000).
[10] A. Bandura \& D. Schunk, J. Pers. Soc. Psy. 41, 586 (1981); V. Sawtelle et al., J. Res. Sci. Teach. 49, 10961121 (2012).

[11] E. Marshman, Z. Kalender, T. Nokes-Malach, C. Schunn, C. Singh., Can. J. Phys; doi: http://dx.doi.org/10.1139/cjp-2017-0185

[12] E. Redish, J. Saul, R. Steinberg Am. J. Phys. 66, 212 (1998).

[13] A. Duckworth \& P. Quinn, J. Per. Assess. 91, 166 (2009).

[14] D. Molden \& C. Dweck, Am. Psy. 61, 192 (2006).

[15] W. Adams, K. Perkins, N. Podolefsky, M. Dubson, N. Finkelstein, C. Wieman, Phys. Rev. ST PER 2, 010101 (2006).

[16] S. Glynn, P. Brickman, N. Armstron, G. Taasoobshirazi, J. Res. Sci. Teach. 48(10), 1159 (2011).

[17] L. Cronbach, Psychomerika 16(3), 297 (1951). 